\title{
Existence of Positive Solutions for a Nonlinear Higher-Order Multipoint Boundary Value Problem
}

\author{
Min Zhao and Yongping Sun \\ College of Electron and Information, Zhejiang University of Media and Communications, Hangzhou, Zhejiang 310018, China \\ Correspondence should be addressed to Yongping Sun; sunyongping@126.com
}

Received 24 January 2014; Accepted 19 March 2014; Published 10 April 2014

Academic Editor: Naseer Shahzad

Copyright (c) 2014 M. Zhao and Y. Sun. This is an open access article distributed under the Creative Commons Attribution License, which permits unrestricted use, distribution, and reproduction in any medium, provided the original work is properly cited.

We study the existence of positive solutions for a nonlinear higher-order multipoint boundary value problem. By applying a monotone iterative method, some existence results of positive solutions are obtained. The main result is illustrated with an example.

\section{Introduction}

We consider the following nonlinear higher-order differential equation:

$$
\begin{array}{r}
u^{(n)}(t)+q(t) f\left(t, u(t), u^{\prime}(t), \ldots, u^{(p)}(t)\right)=0, \\
t \in(0,1),
\end{array}
$$

with the multipoint boundary conditions

$$
\begin{aligned}
& u^{(i)}(0)=0, \quad 0 \leqslant i \leqslant n-2, \\
& u^{(p)}(1)=\sum_{i=1}^{m} k_{i} u^{(p)}\left(\eta_{i}\right), \\
& (1 \leqslant p \leqslant n-2, \text { but fixed }) .
\end{aligned}
$$

Throughout this paper, we assume that the following conditions are satisfied:

(H1) $m \geqslant 1, n \geqslant 3, p \in\{1,2, \ldots, n-2\}$ are fixed integers, $k_{i} \geqslant 0,0<\eta_{i}<1(1 \leqslant i \leqslant m)$ with $\Theta:=\sum_{i=1}^{m} k_{i} \eta_{i}^{n-p-1}<1$;

(H2) $q \in L^{1}[0,1]$ is nonnegative and $0<\int_{0}^{1}(1-$ $s)^{n-p-1} q(s) d s<\infty$;

(H3) $f:[0,1] \times[0, \infty)^{p+1} \rightarrow[0, \infty)$ is continuous.

In this paper, by a positive solution $u^{*}$ of problems (1) and (2), we mean a function $u^{*}$ satisfying the differential equation
(1) and the boundary conditions (2) with $u^{*}(t)>0$ for all $t \in(0,1]$.

The multipoint boundary value problems for ordinary differential equations arise in a variety of different areas of applied mathematics and physics. In recent years, the existence and multiplicity of solutions of nonlinear higherorder differential equations with various multipoint boundary conditions have been studied extensively by numerous researchers using a variety of methods and techniques. For example, Graef and Yang [1] studied a higher-order multipoint boundary value problem

$$
\begin{gathered}
u^{(n)}(t)+\lambda g(t) f(u(t))=0, \quad t \in(0,1), \\
u^{(i)}(0)=0, \quad 0 \leqslant i \leqslant n-2, \\
u^{(n-2)}(1)=\sum_{i=1}^{m} a_{i} u^{(n-2)}\left(\xi_{i}\right),
\end{gathered}
$$

where $n \geqslant 3$ and $m \geqslant 1$ are integers, $a_{i}>0$ for $1 \leqslant i \leqslant m$, and $\sum_{i=1}^{m} a_{i}=1,1 / 2 \leqslant \xi_{1}<\xi_{2}<\cdots<\xi_{m}<1, \lambda>$ 0 , is a parameter. Some existence and nonexistence results of positive solutions were obtained by using Krasnosel'skii's fixed point theorem. In [2], by applying fixed point index theory, Pang et al. studied the expression and properties 
of Green's function and obtained the existence of positive solutions for $n$ th-order $m$-point boundary value problems

$$
\begin{gathered}
u^{(n)}(t)+f(t, u(t))=0, \quad t \in(0,1), \\
u^{(i)}(0)=0, \quad 0 \leqslant i \leqslant n-2, \\
u(1)=\sum_{i=1}^{m-2} k_{i} u\left(\xi_{i}\right),
\end{gathered}
$$

where $n \geqslant 2, k_{i}>0(i=1,2, \ldots, m-2), 0<\xi_{1}<\xi_{2}<$ $\cdots<\xi_{m}<1$ with $0<\sum_{i=1}^{m-2} k_{i} \xi_{i}^{n-1}<1$. Guo et al. in [3] imposed growth conditions on the nonlinearity $f$ which yield the existence of multiple positive solutions by using the Leggett-Williams fixed point theorem. Li and Wei in [4] and Yang and Wei in [5] improved and generalized the results of [2] by using different methods. Graef et al. [6] considered an $n$ th-order multipoint boundary value problem

$$
\begin{gathered}
u^{(n)}+f\left(t, u, u^{\prime}, \ldots, u^{(n-1)}\right)=\lambda p(t), \quad t \in(0,1), \\
u^{(i)}(0)=A_{i}, \quad i=0,1, \ldots, n-3, \\
u^{(n-2)}(0)-\sum_{j=1}^{m} a_{j} u^{(n-2)}\left(t_{j}\right)=A_{n-2}, \\
u^{(n-2)}(1)-\sum_{j=1}^{m} b_{j} u^{(n-2)}\left(t_{j}\right)=A_{n-1},
\end{gathered}
$$

where $n \geqslant 2$ and $m \geqslant 1$ are integers, $\lambda \in \mathbb{R}$ is a parameter, $f \in C\left([0,1] \times \mathbb{R}^{n}\right), p \in C(0,1)$ with $p(t)>0$ on $[0,1]$, $A_{i} \in \mathbb{R}$ for $i=0,1, \ldots, n-1$, and $a_{j}, b_{j} \in \mathbb{R}^{+}:=[0, \infty)$ for $j=1,2, \ldots, m$. Sufficient conditions were obtained for the existence of one solution and two solutions of the problem for different values of $\lambda$. The analysis mainly relies on the lower and upper solution method and topological degree theory. The results extended and improved some recent work in the literature. In a recent paper [7], we study problems (1) and (2) with $m=1$ by a fixed point theorem of cone expansion and compression of functional type according to Avery et al. [8]. For other existence results of positive solutions for higherorder multipoint problems, for a small sample of such work, we refer the reader to Ahmad and Ntouyas [9], Anderson et al. [10], Davis et al. [11], Du et al. [12, 13], Eloe and Henderson [14], Fu and Du [15], Graef et al. [16, 17], Henderson and Luca [18], Ji and Guo [19], Jiang [20], Liu et al. [21], Liu and Ge [22], Liu et al. [23], Palamides [24], Su and Wang [25], Zhang et al. [26], and Zhang [27] and the references therein.

We noticed that the main tools employed in abovementioned works are various fixed point theorems, such as Krasnosel'skii, Leggett-Williams, and Avery and Peterson. Recently, the monotone iterative method has been successfully employed to prove the existence of positive solutions of nonlinear boundary value problems for ordinary differential equations. For example, Ma et al. [28] proved the existence of positive solutions of some multipoint $p$-Laplacian boundary value problems via monotone iterative method. Ma and Yang [29] obtained the existence of positive solutions and established two corresponding iterative schemes for a thirdorder three-point boundary value problem with increasing homeomorphism and positive homomorphism. Sun and Ge [30] applied monotone iterative procedure to prove the existence of positive pseudosymmetric solutions for a threepoint second-order $p$-Laplacian boundary value problem. Sun et al. [31] proved the existence of positive solutions for some fourth-order two-point boundary value problems via monotone iterative technique. Yao $[32,33]$ obtained a successively iterative scheme of positive solution of Lidstone boundary value problem and a beam equation with nonhomogeneous boundary condition, respectively. In this paper, we will study the existence and iteration of positive solutions for problems (1) and (2) by using the monotone iterative method. The monotone iterative scheme can be developed into a computational algorithm for numerical solutions.

\section{Basic Lemmas}

In this section, we present two lemmas, related to the following higher-order differential equation with multipoint boundary conditions:

$$
\begin{gathered}
u^{(n)}(t)+h(t)=0, \quad t \in(0,1), \\
u^{(i)}(0)=0, \quad 0 \leqslant i \leqslant n-2, \\
u^{(p)}(1)=\sum_{i=1}^{m} k_{i} u^{(p)}\left(\eta_{i}\right) .
\end{gathered}
$$

Lemma 1. Let $h \in C[0,1]$ be a given function; then the solution of problems (6) and (7) is given by

$$
u(t)=\int_{0}^{1} G(t, s) h(s) d s
$$

where

$$
G(t, s)=G_{1}(t, s)+G_{2}(t, s)
$$

$$
\begin{gathered}
G_{1}(t, s) \\
=\frac{1}{(n-1) !} \begin{cases}t^{n-1}(1-s)^{n-p-1}-(t-s)^{n-1}, & s \leqslant t, \\
t^{n-1}(1-s)^{n-p-1}, & t \leqslant s,\end{cases} \\
G_{2}(t, s)=\frac{t^{n-1}}{(n-1) !(1-\Theta)} \sum_{i=1}^{m} k_{i} H\left(\eta_{i}, s\right), \\
H\left(\eta_{i}, s\right)= \begin{cases}\eta_{i}^{n-p-1}(1-s)^{n-p-1}-\left(\eta_{i}-s\right)^{n-p-1}, & 0 \leqslant s \leqslant \eta_{i}, \\
\eta_{i}^{n-p-1}(1-s)^{n-p-1}, & \eta_{i} \leqslant s \leqslant 1 .\end{cases}
\end{gathered}
$$

Proof. The solution of (6) is

$$
u(t)=-\frac{1}{(n-1) !} \int_{0}^{t}(t-s)^{n-1} h(s) d s+A t^{n-1}+\sum_{i=0}^{n-2} A_{i} t^{i},
$$


for some $A, A_{i} \in \mathbb{R}(i=0,1,2, \ldots, n-2)$. Noting that the conditions are $u(0)=u^{\prime}(0)=\cdots=u^{(n-2)}(0)=0$, we obtain $A_{0}=A_{1}=\cdots=A_{n-2}=0$. Consequently, the general solution of problems (6) and (7) is

$$
u(t)=-\frac{1}{(n-1) !} \int_{0}^{t}(t-s)^{n-1} h(s) d s+A t^{n-1}
$$

Therefore, by (14), we have

$$
\begin{aligned}
u^{(p)}(t)= & -\frac{1}{(n-p-1) !} \int_{0}^{t}(t-s)^{n-p-1} h(s) d s \\
& +\frac{(n-1) !}{(n-p-1) !} A t^{n-p-1}
\end{aligned}
$$

which implies that

$$
\begin{aligned}
u^{(p)}(1)= & -\frac{1}{(n-p-1) !} \int_{0}^{1}(1-s)^{n-p-1} h(s) d s \\
& +\frac{(n-1) !}{(n-p-1) !} A, \\
u^{(p)}\left(\eta_{i}\right)= & -\frac{1}{(n-p-1) !} \int_{0}^{\eta_{i}}\left(\eta_{i}-s\right)^{n-p-1} h(s) d s \\
& +\frac{(n-1) !}{(n-p-1) !} A \eta_{i}^{n-p-1} .
\end{aligned}
$$

By the condition $u^{(p)}(1)=\sum_{i=1}^{m} k_{i} u^{(p)}\left(\eta_{i}\right),(16)$ and (17), we deduce

$$
\begin{aligned}
A= & \frac{1}{(n-1) !(1-\Theta)}\left[\int_{0}^{1}(1-s)^{n-p-1} h(s) d s\right. \\
& \left.-\sum_{i=1}^{m} k_{i} \int_{0}^{\eta_{i}}\left(\eta_{i}-s\right)^{n-p-1} h(s) d s\right] \\
= & \frac{1}{(n-1) !} \int_{0}^{1}(1-s)^{n-p-1} h(s) d s \\
& +\frac{\sum_{i=1}^{m} k_{i} \eta_{i}^{n-p-1}}{(n-1) !(1-\Theta)} \int_{0}^{1}(1-s)^{n-p-1} h(s) d s \\
& -\frac{1}{(n-1) !(1-\Theta)} \sum_{i=1}^{m} k_{i} \int_{0}^{\eta_{i}}\left(\eta_{i}-s\right)^{n-p-1} h(s) d s \\
= & \frac{1}{(n-1) !} \int_{0}^{1}(1-s)^{n-p-1} h(s) d s \\
& +\frac{1}{(n-1) !(1-\Theta)} \sum_{i=1}^{m} k_{i} \int_{0}^{1} H\left(\eta_{i}, s\right) h(s) d s .
\end{aligned}
$$

Substituting (18) into (14), we obtain the unique solution $u(t)$ of problems (6) and (7) as

$$
\begin{aligned}
u(t)= & -\frac{1}{(n-1) !} \int_{0}^{t}(t-s)^{n-1} h(s) d s \\
& +\frac{t^{n-1}}{(n-1) !} \int_{0}^{1}(1-s)^{n-p-1} h(s) d s \\
& +\frac{t^{n-1}}{(n-1) !(1-\Theta)} \sum_{i=1}^{m} k_{i} \int_{0}^{1} H\left(\eta_{i}, s\right) h(s) d s
\end{aligned}
$$

$$
\begin{aligned}
& =\int_{0}^{1} G_{1}(t, s) h(s) d s+\int_{0}^{1} G_{2}(t, s) h(s) d s \\
& =\int_{0}^{1} G(t, s) h(s) d s .
\end{aligned}
$$

The proof is completed.

Lemma 2. Green's function $G(t, s)$ defined by (9) has the following properties:

(i) $\partial^{j} G(t, s) / \partial t^{j}$ is continuous on $[0,1] \times[0,1], j=0,1$, $2, \ldots, n-2$;

(ii) $0 \leqslant \partial^{j} G(t, s) / \partial t^{j} \leqslant\left(t^{n-j-1} /(n-j-1) !(1-\Theta)\right)(1-$ $s)^{n-p-1}$, for all $t, s \in[0,1], j=0,1,2, \ldots, p$;

(iii) $t^{n-1} G(1, s) \leqslant G(t, s) \leqslant G(1, s)$, for all $t, s \in[0,1]$.

Proof. The statement (i) is obvious. For the proof of the statement (ii), we note that, for all $t, s \in[0,1]$, if $t \leqslant s$, from definition, it is clear that $\partial^{j} G_{1}(t, s) / \partial t^{j} \geqslant 0$ for $j=$ $0,1,2, \ldots, n-1$. If $s \leqslant t$, from (10), we obtain that

$$
\begin{aligned}
\frac{\partial^{j} G_{1}(t, s)}{\partial t^{j}} & =\frac{1}{(n-j-1) !}\left[t^{n-j-1}(1-s)^{n-p-1}-(t-s)^{n-j-1}\right] \\
& \geqslant \frac{1}{(n-j-1) !}\left[t^{n-j-1}(1-s)^{n-j-1}-(t-s)^{n-j-1}\right] \\
& \geqslant \frac{1}{(n-j-1) !}\left[(t-t s)^{n-j-1}-(t-s)^{n-j-1}\right] \\
& \geqslant 0, \quad j=0,1,2, \ldots, p .
\end{aligned}
$$

For any $i=1,2, \ldots, m$, if $s \geqslant \eta_{i}$, from (12), it is obvious that $H\left(\eta_{i}, s\right) \geqslant 0$. If $s \leqslant \eta_{i}$, from (12), we have

$$
\begin{aligned}
\eta_{i}^{n-p-1} & (1-s)^{n-p-1}-\left(\eta_{i}-s\right)^{n-p-1} \\
& =\left(\eta_{i}-\eta_{i} s\right)^{n-p-1}-\left(\eta_{i}-s\right)^{n-p-1} \geqslant 0,
\end{aligned}
$$

which implies that

$$
H\left(\eta_{i}, s\right) \geqslant 0, \quad s \in[0,1], i=1,2, \ldots, m
$$

By (20) and (22), we get

$$
\begin{aligned}
\frac{\partial^{j} G(t, s)}{\partial t^{j}} & =\frac{\partial^{j} G_{1}(t, s)}{\partial t^{j}}+\frac{\partial^{j} G_{2}(t, s)}{\partial t^{j}} \\
& =\frac{\partial^{j} G_{1}(t, s)}{\partial t^{j}}+\frac{t^{n-j-1}}{(n-j-1) !(1-\Theta)} \sum_{i=1}^{m-2} k_{i} H\left(\eta_{i}, s\right) \\
& \geqslant 0, \quad t, s \in[0,1], j=0,1,2, \ldots, p .
\end{aligned}
$$


On the other hand, by (10) and (12), we find that

$$
\begin{gathered}
\frac{\partial^{j} G_{1}(t, s)}{\partial t^{j}} \leqslant \frac{t^{n-j-1}}{(n-j-1) !}(1-s)^{n-p-1}, \\
t, s \in[0,1], \quad j=0,1,2, \ldots, n-2, \\
H\left(\eta_{i}, s\right) \leqslant \eta_{i}^{n-p-1}(1-s)^{n-p-1}, \quad s \in[0,1], i=1,2, \ldots, m .
\end{gathered}
$$

Therefore,

$$
\begin{aligned}
\frac{\partial^{j} G(t, s)}{\partial t^{j}}= & \frac{\partial^{j} G_{1}(t, s)}{\partial t^{j}}+\frac{\partial^{j} G_{2}(t, s)}{\partial t^{j}} \\
\leqslant & \frac{t^{n-j-1}}{(n-j-1) !}(1-s)^{n-p-1} \\
& +\frac{t^{n-j-1}}{(n-j-1) !(1-\Theta)} \sum_{i=1}^{m} k_{i} H\left(\eta_{i}, s\right) \\
\leqslant & \frac{t^{n-j-1}}{(n-j-1) !}(1-s)^{n-p-1} \\
& +\frac{t^{n-j-1}}{(n-j-1) !(1-\Theta)} \sum_{i=1}^{m} k_{i} \eta_{i}^{n-p-1}(1-s)^{n-p-1} \\
\leqslant & \frac{t^{n-j-1}}{(n-j-1) !}(1-s)^{n-p-1} \\
& +\frac{\Theta t^{n-j-1}}{(n-j-1) !(1-\Theta)}(1-s)^{n-p-1} \\
= & \frac{t t^{n-j-1}}{(n-j-1) !(1-\Theta)}(1-s)^{n-p-1}, \\
& \frac{t, 1], j=0,1,2, \ldots, n-2 .}{(0,1]},
\end{aligned}
$$

In view of (23) and (25), we have the assertion.

Now, we prove the statement (iii). In fact, from the statement (ii), we know that $\partial G(t, s) / \partial t \geqslant 0$ for any $t, s \in$ $[0,1]$. Thus, $G(t, s)$ is nondecreasing with respect to $t$ for any $s \in[0,1]$. Consequently,

$$
G(t, s) \leqslant G(1, s), \quad \text { for any }(t, s) \in[0,1] \times[0,1] .
$$

If $s \leqslant t$, then, from (10), we have

$$
\begin{aligned}
G_{1}(t, s)= & \frac{1}{(n-1) !}\left[t^{n-1}(1-s)^{n-p-1}-(t-s)^{n-1}\right] \\
= & \frac{t^{n-1}}{(n-1) !}\left[(1-s)^{n-p-1}-(1-s)^{n-1}\right] \\
& +\frac{1}{(n-1) !}\left[(t-t s)^{n-1}-(t-s)^{n-1}\right] \\
\geqslant & \frac{t^{n-1}}{(n-1) !}\left[(1-s)^{n-p-1}-(1-s)^{n-1}\right] \\
= & t^{n-1} G_{1}(1, s) .
\end{aligned}
$$

Also, if $s \geqslant t$, from (10), we have

$$
\begin{aligned}
G_{1}(t, s)= & \frac{1}{(n-1) !} t^{n-1}(1-s)^{n-p-1} \\
= & \frac{t^{n-1}}{(n-1) !}\left[(1-s)^{n-p-1}-(1-s)^{n-1}\right] \\
& +\frac{1}{(n-1) !}(t-t s)^{n-1} \\
\geqslant & \frac{t^{n-1}}{(n-1) !}\left[(1-s)^{n-p-1}-(1-s)^{n-1}\right] \\
= & t^{n-1} G_{1}(1, s) .
\end{aligned}
$$

Thus, from (27) and (28), we obtain

$$
G_{1}(t, s) \geqslant t^{n-1} G_{1}(1, s),
$$

which together with (9) and (11) implies

$$
\begin{aligned}
G(t, s)= & G_{1}(t, s) \\
& +\frac{t^{n-1}}{(n-1) !\left(1-\sum_{i=1}^{m-2} k_{i} \eta_{i}^{n-p-1}\right)} \sum_{i=1}^{m} k_{i} H\left(\eta_{i}, s\right) \\
\geqslant & t^{n-1} G_{1}(1, s) \\
& +\frac{t^{n-1}}{(n-1) !\left(1-\sum_{i=1}^{m-2} k_{i} \eta_{i}^{n-p-1}\right)} \sum_{i=1}^{m} k_{i} H\left(\eta_{i}, s\right) \\
= & t^{n-1} G(1, s) .
\end{aligned}
$$

Inequations (26) and (30) show that the statement (iii) is true. Then, the proof is completed.

\section{Main Results}

In this section, we consider the existence of positive solutions for problems (1) and (2) by using the monotone iterative method. In the sequel, for any $u \in C[0,1]$, we define $\|u\|_{\infty}=$ $\max _{0 \leqslant t \leqslant 1}|u(t)|$. Let $E=C^{p}[0,1]$ be a Banach space with the norm

$$
\|u\|=\max \left\{\|u\|_{\infty},\left\|u^{\prime}\right\|_{\infty}, \ldots,\left\|u^{(p)}\right\|_{\infty}\right\}
$$

We define a cone $P \subset E$ by

$$
\begin{gathered}
P=\left\{u \in C^{p}[0,1]: u(t) \geqslant t^{n-1}\|u\|_{\infty}, u^{(j)}(t) \geqslant 0, t \in[0,1],\right. \\
j=0,1,2, \ldots, p\},
\end{gathered}
$$

and an integral operator $T: P \rightarrow E$ by

$$
\begin{array}{r}
(T u)(t)=\int_{0}^{1} G(t, s) q(s) f\left(s, u(s), u^{\prime}(s), \ldots, u^{(p)}(s)\right) d s, \\
u \in C^{p}[0,1] .
\end{array}
$$


Obviously, the fixed points of $T$ are nonnegative solutions of problems (1) and (2). Applying Ascoli-Arzelà theorem and a standard argument, we can prove that $T$ is completely continuous.

For any $u \in P$, it flows from Lemma 2 (iii) that

$$
\begin{array}{r}
(T u)(t)=\int_{0}^{1} G(t, s) q(s) f\left(s, u(s), u^{\prime}(s), \ldots, u^{(p)}(s)\right) d s \\
\leqslant \int_{0}^{1} G(1, s) q(s) f\left(s, u(s), u^{\prime}(s), \ldots, u^{(p)}(s)\right) d s \\
t \in[0,1]
\end{array}
$$

which implies that

$$
\|T u\|_{\infty} \leqslant \int_{0}^{1} G(1, s) q(s) f\left(s, u(s), u^{\prime}(s), \ldots, u^{(p)}(s)\right) d s .
$$

On the other hand, by Lemma 2 (iii), we have

$$
\begin{gathered}
(T u)(t)=\int_{0}^{1} G(t, s) q(s) f\left(s, u(s), u^{\prime}(s), \ldots, u^{(p)}(s)\right) d s \\
\geqslant t^{n-1} \int_{0}^{1} G(1, s) q(s) \\
\quad \times f\left(s, u(s), u^{\prime}(s), \ldots, u^{(p)}(s)\right) d s, \\
t \in[0,1],
\end{gathered}
$$

which together with (35) implies

$$
(T u)(t) \geqslant t^{n-1}\|T u\|_{\infty}, \quad t \in[0,1]
$$

In addition, it follows from Lemma 2 (ii) that

$$
\begin{aligned}
(T u)^{(j)}(t)= & \int_{0}^{1} \frac{\partial^{j} G(t, s)}{\partial t^{j}} q(s) \\
& \times f\left(s, u(s), u^{\prime}(s), \ldots, u^{(p)}(s)\right) d s \geqslant 0, \\
& j=0,1,2, \ldots, p .
\end{aligned}
$$

Therefore, (37) and (38) indicate that $T u \in P$.

For convenience, we introduce the following notation:

$$
\Lambda=\left(\frac{1}{1-\Theta} \int_{0}^{1}(1-s)^{n-p-1} q(s) d s\right)^{-1}
$$

The conditions (H1) and (H2) indicate that $\Lambda$ is well defined and $\Lambda>0$.

Theorem 3. Suppose (H1), (H2), and (H3) hold. Assume that $f(t, 0,0, \ldots, 0) \neq 0$ and there exists constant $a>0$, such that

\footnotetext{
(H4) $f\left(t, x_{0}, x_{1}, \ldots, x_{p}\right) \leqslant f\left(t, y_{0}, y_{1}, \ldots, y_{p}\right)$, for $0 \leqslant x_{j} \leqslant$ $y_{j} \leqslant a, t \in[0,1], j=0,1,2, \ldots, p$

(H5) $\max _{0 \leqslant t \leqslant 1} f(t, a, a, \ldots, a) \leqslant \Lambda a$.
}

Then, problems (1) and (2) possess at least two positive solutions $w^{*}$ and $v^{*}$, such that

(i) $0<\left\|w^{*}\right\| \leqslant$ a and $\lim _{k \rightarrow \infty} T^{k} w_{0}=w^{*}$, where $w_{0}(t)=$ $a t^{n-1} /(n-1) !, t \in[0,1]$;

(ii) $0<\left\|v^{*}\right\| \leqslant a$ and $\lim _{k \rightarrow \infty} T^{k} v_{0}=v^{*}$, where $v_{0}(t)=$ $0, t \in[0,1]$.

Proof. We define $P_{a}=\{u \in P:\|u\| \leqslant a\}$. In what follows, we first prove $T: P_{a} \rightarrow P_{a}$. In fact, if $u \in P_{a}$, then $\|u\| \leqslant a$; thus

$$
0 \leqslant u^{(j)}(s) \leqslant\|u\| \leqslant a, \quad s \in[0,1], j=0,1,2, \ldots, p .
$$

By assumptions (H4) and (H5), we have

$$
\begin{aligned}
0 & \leqslant f\left(s, u(s), u^{\prime}(s), \ldots, u^{(p)}(s)\right) \leqslant f(s, a, \ldots, a) \\
& \leqslant \max _{0 \leqslant s \leqslant 1} f(s, a, \ldots, a) \leqslant \Lambda a, \quad s \in[0,1] .
\end{aligned}
$$

Thus, by the definition of $T$ and Lemma 2 (ii), for $j=0,1$, $2, \ldots, p$, we get

$$
\begin{aligned}
0 & \leqslant(T u)^{(j)}(t) \\
& =\int_{0}^{1} \frac{\partial^{j} G(t, s)}{\partial t^{j}} q(s) f\left(s, u(s), u^{\prime}(s), \ldots, u^{(p)}(s)\right) d s \\
& \leqslant \frac{t^{n-j-1}}{(n-j-1) !(1-\Theta)} \int_{0}^{1}(1-s)^{n-p-1} q(s) f(s, a, \ldots, a) d s \\
& \leqslant \frac{1}{1-\Theta} \Lambda a \int_{0}^{1}(1-s)^{n-p-1} q(s) d s=a, \quad t \in[0,1] .
\end{aligned}
$$

Then, (42) shows that $\|T u\| \leqslant a$; thus we get $T: P_{a} \rightarrow P_{a}$.

Let $v_{0}=0$; then it is evident that $v_{0} \in P_{a}$. Let $v_{k+1}=T v_{k}(k=0,1,2, \ldots)$. The fact that $T: P_{a} \rightarrow P_{a}$ implies that $v_{k} \in T\left(P_{a}\right) \subseteq P_{a}(k=1,2, \ldots)$. Since $T$ is completely continuous, we assert that the sequence $\left\{v_{k}\right\}_{k=1}^{\infty}$ has a convergent subsequence $\left\{v_{k_{i}}\right\}_{i=1}^{\infty}$ such that $\lim _{i \rightarrow \infty} v_{k_{i}}=$ $v^{*} \in P_{a}$.

Since $v_{1}=T v_{0}=T 0 \in P_{a}$, we have

$$
\begin{aligned}
a & \geqslant v_{1}^{(j)}(t)=\left(T v_{0}\right)^{(j)}(t)=(T 0)^{(j)}(t) \\
& \geqslant 0=v_{0}^{(j)}(t), \quad t \in[0,1], j=0,1,2, \ldots, p .
\end{aligned}
$$

So, by (H4), one has

$$
\begin{array}{r}
v_{2}^{(j)}(t)=\left(T v_{1}\right)^{(j)}(t) \geqslant\left(T v_{0}\right)^{(j)}(t)=v_{1}^{(j)}(t), \quad t \in[0,1] \\
j=0,1,2, \ldots, p
\end{array}
$$

Thus, by the induction, we have

$$
\begin{array}{r}
v_{k+1}^{(j)}(t) \geqslant v_{k}^{(j)}(t), \quad t \in[0,1], j=0,1,2, \ldots, p, \\
k=0,1,2, \ldots .
\end{array}
$$


Hence, $\lim _{k \rightarrow \infty} v_{k}=v^{*}$. Applying the continuity of $T$ and taking the limit $k \rightarrow \infty$ in $v_{k+1}=T v_{k}$, we get $T v^{*}=v^{*}$.

Let $w_{0}(t)=a t^{n-1} /(n-1) !, t \in[0,1]$, and $w_{k+1}=T w_{k}$ $(k=0,1,2, \ldots)$. Then, $w_{0} \in P_{a}$. Since $T: P_{a} \rightarrow P_{a}$, we have $w_{k} \in T\left(P_{a}\right) \subseteq P_{a}(k=1,2, \ldots)$. Since $T$ is completely continuous, we assert that the sequence $\left\{w_{k}\right\}_{k=1}^{\infty}$ has a convergent subsequence $\left\{w_{k_{i}}\right\}_{i=1}^{\infty}$ such that $\lim _{i \rightarrow \infty} w_{k_{i}}=$ $w^{*} \in P_{a}$.

Since $w_{1}=T w_{0} \in P_{a}$, by Lemma 2 (ii) and (H4) and (H5), for $j=0,1,2, \ldots, p$, we have

$$
\begin{aligned}
& \left(T w_{0}\right)^{(j)}(t) \\
& =\int_{0}^{1} \frac{\partial^{j} G(t, s)}{\partial t^{j}} q(s) f\left(s, w_{0}(s), w_{0}^{\prime}(s), \ldots, w_{0}^{(p)}(s)\right) d s \\
& \leqslant \frac{t^{n-j-1}}{(n-j-1) !(1-\Theta)} \\
& \quad \times \int_{0}^{1}(1-s)^{n-p-1} q(s) f(s, a, \ldots, a) d s \\
& \leqslant \frac{w_{0}^{(j)}(t)}{1-\Theta} \Lambda \int_{0}^{1}(1-s)^{n-p-1} q(s) d s=w_{0}^{(j)}(t), \\
& \quad t \in[0,1] .
\end{aligned}
$$

Thus, we obtain that

$$
w_{1}^{(j)}(t) \leqslant w_{0}^{(j)}(t), \quad t \in[0,1], j=0,1,2, \ldots, p .
$$

So, by Lemma 2 (ii) and (H4), we have

$$
\begin{aligned}
w_{2}^{(j)}(t) & \\
= & \left(T w_{1}\right)^{(j)}(t) \\
& =\int_{0}^{1} \frac{\partial^{j} G(t, s)}{\partial t^{j}} q(s) f\left(s, w_{1}(s), w_{1}^{\prime}(s), \ldots, w_{1}^{(p)}(s)\right) d s \\
& \leqslant \int_{0}^{1} \frac{\partial^{j} G(t, s)}{\partial t^{j}} q(s) f\left(s, w_{0}(s), w_{0}^{\prime}(s), \ldots, w_{0}^{(p)}(s)\right) d s \\
& =\left(T w_{0}\right)^{(j)}(t)=w_{1}^{(j)}(t), \quad t \in[0,1], j=0,1,2, \ldots, p .
\end{aligned}
$$

By the induction, we have

$$
\begin{array}{r}
w_{k+1}^{(j)}(t) \leqslant w_{k}^{(j)}(t), \quad t \in[0,1], j=0,1,2, \ldots, p, \\
k=0,1,2, \ldots
\end{array}
$$

Hence, $\lim _{k \rightarrow \infty} w_{k}=w^{*}$. Applying the continuity of $T$ and $w_{k+1}=T w_{k}$, we get $T w^{*}=w^{*}$.

Furthermore, assumption $f(t, 0,0, \ldots, 0) \quad \not \equiv 0$ implies that the zero function is not a solution of problems (1) and (2); thus $\left\|w^{*}\right\|_{\infty}>0,\left\|v^{*}\right\|_{\infty}>0$. The definition of the cone $P$ follows that we have $w^{*}(t) \geqslant t^{n-1}\left\|w^{*}\right\|_{\infty}>0, v^{*}(t) \geqslant$ $t^{n-1}\left\|v^{*}\right\|_{\infty}>0, t \in(0,1]$. Thus, $w^{*}$ and $v^{*}$ are positive solutions of problems (1) and (2). The proof is completed.
Remark 4. The iterative sequences in Theorem 3 start off with the zero function and a known simple function, respectively.

Remark 5. We can easily get that $w^{*}$ and $v^{*}$ are the maximal and minimal solution of problems (1) and (2) in $P_{a}$. Of course, $w^{*}=v^{*}$ may happen and then problems (1) and (2) have only one solution in $P_{a}$.

\section{Example}

Example 1. Consider the fourth-order four-point boundary value problem

$$
\begin{gathered}
u^{\prime \prime \prime \prime}(t)+\frac{2}{9}\left[t+u^{2}(t)+t u^{\prime}(t)+u^{\prime \prime}(t)\right]=0, \quad t \in(0,1) \\
u(0)=u^{\prime}(0)=u^{\prime \prime}(0)=0 \\
u^{\prime \prime}(1)=u^{\prime \prime}\left(\frac{1}{4}\right)+\frac{1}{2} u^{\prime \prime}\left(\frac{1}{2}\right)
\end{gathered}
$$

In this problem, $n=4, m=2, p=2, k_{1}=1, k_{2}=1 / 2$, $\eta_{1}=1 / 4, \eta_{2}=1 / 2, q(t) \equiv 2 / 9$, and $f\left(t, x_{0}, x_{1}, x_{2}\right)=t+$ $x_{0}^{2}+t x_{1}+x_{2}$. It is obvious that (H1)-(H3) hold. By direct calculation, we get

$$
\Lambda=\left(\frac{1}{1-\Theta} \int_{0}^{1}(1-s)^{n-p-1} q(s) d s\right)^{-1}=\frac{9}{2} .
$$

Choose $a=2$; then it is easy to check that (H4) and (H5) hold. Thus, all the conditions of Theorem 3 are satisfied. By Theorem 3, problem (50) has two positive solutions $v^{*}$ and $w^{*}$, such that $0<\left\|v^{*}\right\| \leqslant 2,0<\left\|w^{*}\right\| \leqslant 2, \lim _{k \rightarrow \infty} v_{k}=v^{*}$, and $\lim _{k \rightarrow \infty} w_{k}=w^{*}$.

The two iterative sequences are as follows:

$$
v_{0}(t)=0, \quad t \in[0,1],
$$

$$
\begin{gathered}
v_{k+1}(t) \\
=-\frac{1}{27} \int_{0}^{t}(t-s)^{3}\left[s+v_{k}^{2}(s)+s v_{k}^{\prime}(s)+v_{k}^{\prime \prime}(s)\right] d s \\
+\frac{2 t^{3}}{27}\left[\int_{0}^{1}(1-s)\left[s+v_{k}^{2}(s)+s v_{k}^{\prime}(s)+v_{k}^{\prime \prime}(s)\right] d s\right. \\
-\int_{0}^{1 / 4}\left(\frac{1}{4}-s\right)\left[s+v_{k}^{2}(s)+s v_{k}^{\prime}(s)+v_{k}^{\prime \prime}(s)\right] d s \\
\quad-\frac{1}{2} \int_{0}^{1 / 2}\left(\frac{1}{2}-s\right) \\
\left.\times\left[s+v_{k}^{2}(s)+s v_{k}^{\prime}(s)+v_{k}^{\prime \prime}(s)\right] d s\right] \\
w_{0}(t)=\frac{1}{3} t^{3}, \quad t \in[0,1], \quad k=0,1,2, \ldots,
\end{gathered}
$$




$$
\begin{array}{r}
w_{k+1}(t) \\
=-\frac{1}{27} \int_{0}^{t}(t-s)^{3}\left[s+w_{k}^{2}(s)+s w_{k}^{\prime}(s)+w_{k}^{\prime \prime}(s)\right] d s \\
+\frac{2 t^{3}}{27}\left[\int_{0}^{1}(1-s)\left[s+v_{k}^{2}(s)+s v_{k}^{\prime}(s)+v_{k}^{\prime \prime}(s)\right] d s\right. \\
-\int_{0}^{1 / 4}\left(\frac{1}{4}-s\right) \\
\quad \times\left[s+w_{k}^{2}(s)+s w_{k}^{\prime}(s)+w_{k}^{\prime \prime}(s)\right] d s \\
\quad \frac{1}{2} \int_{0}^{1 / 2}\left(\frac{1}{2}-s\right) \\
\left.\quad \times\left[s+w_{k}^{2}(s)+s w_{k}^{\prime}(s)+w_{k}^{\prime \prime}(s)\right] d s\right] \\
\quad t \in[0,1], \quad k=0,1,2, \ldots
\end{array}
$$

The second and third terms of the two schemes are as follows:

$$
\begin{aligned}
& v_{1}(t)=\frac{59}{5184} t^{3}-\frac{1}{540} t^{5}, \\
& v_{2}(t)=\frac{59}{5184} t^{3}-\frac{1}{540} t^{5}+\frac{45253}{11609505792} t^{9} \\
& -\frac{3481}{2902376448} t^{10}-\frac{767}{604661760} t^{11} \\
& +\frac{59}{151165440} t^{12}+\frac{13}{125971200} t^{13} \\
& -\frac{1}{31492800} t^{14} \\
& w_{1}(t)=\frac{84571643}{2229534720} t^{3}-\frac{1}{180} t^{5}-\frac{1}{3780} t^{7}-\frac{1}{204120} t^{10}, \\
& w_{2}(t)=\frac{59}{5184} t^{3}-\frac{1}{540} t^{5}+\frac{92980716396352837}{2147396429240126668800} t^{9} \\
& -\frac{7152362799719449}{536849107310031667200} t^{10} \\
& -\frac{1099431359}{86684309913600} t^{11}+\frac{84571643}{21671077478400} t^{12} \\
& +\frac{591299137}{1820370508185600} t^{13}-\frac{45484549}{455092627046400} t^{14} \\
& +\frac{13}{146966400} t^{15}-\frac{3774873023}{98300007442022400} t^{16} \\
& +\frac{136328699}{24575001860505600} t^{17}+\frac{11}{11110659840} t^{18} \\
& -\frac{1}{1984046400} t^{19}+\frac{13}{166659897600} t^{20} \\
& -\frac{1}{41664974400} t^{21}+\frac{13}{17999268940800} t^{23} \\
& -\frac{1}{4499817235200} t^{24} \text {. }
\end{aligned}
$$

\section{Conflict of Interests}

The authors declare that there is no conflict of interests regarding the publication of this paper.

\section{Acknowledgments}

The authors would like to express their thanks to the anonymous referee for her/his valuable suggestions and comments. This research was partially supported by the Natural Science Foundation of Zhejiang Province of China (LY12A01012).

\section{References}

[1] J. R. Graef and B. Yang, "Positive solutions to a multi-point higher order boundary value problem," Journal of Mathematical Analysis and Applications, vol. 316, no. 2, pp. 409-421, 2006.

[2] C. Pang, W. Dong, and Z. Wei, "Green's function and positive solutions of $n$th order $m$-point boundary value problem," Applied Mathematics and Computation, vol. 182, no. 2, pp. 12311239, 2006.

[3] Y. Guo, Y. Ji, and J. Zhang, "Three positive solutions for a nonlinear $n$ th-order $m$-point boundary value problem," Nonlinear Analysis: Theory, Methods \& Applications, vol. 68, no. 11, pp. 3485-3492, 2008.

[4] Y. Li and Z. Wei, "Multiple positive solutions for $n$th order multipoint boundary value problem," Boundary Value Problems, vol. 2010, Article ID 708376, 13 pages, 2010.

[5] J. Yang and Z. Wei, "Positive solutions of $n$th order $m$-point boundary value problem," Applied Mathematics and Computation, vol. 202, no. 2, pp. 715-720, 2008.

[6] J. R. Graef, L. Kong, and B. Yang, "Existence of solutions for a higher order multi-point boundary value problem," Results in Mathematics, vol. 53, no. 1-2, pp. 77-101, 2009.

[7] Y. Sun, Q. Sun, and X. Zhang, "Existence and nonexistence of positive solutions for a higher-order three-point boundary value problem," Abstract and Applied Analysis, vol. 2014, Article ID 513051, 7 pages, 2014.

[8] R. Avery, J. Henderson, and D. O'Regan, "Functional compression-expansion fixed point theorem," Electronic Journal of Differential Equations, vol. 2008, 12 pages, 2008.

[9] B. Ahmad and S. K. Ntouyas, "A study of higher-order nonlinear ordinary differential equations with four-point nonlocal integral boundary conditions," Journal of Applied Mathematics and Computing, vol. 39, no. 1-2, pp. 97-108, 2012.

[10] D. R. Anderson, T. O. Anderson, and M. M. Kleber, “Green's function and existence of solutions for a functional focal differential equation," Electronic Journal of Differential Equations, vol. 2006, no. 12, 14 pages, 2006.

[11] J. M. Davis, P. W. Eloe, and J. Henderson, "Triple positive solutions for multipoint conjugate boundary value problems," Georgian Mathematical Journal, vol. 6, no. 5, pp. 415-420, 1999.

[12] Z. Du, W. Liu, and X. Lin, "Multiple solutions to a three-point boundary value problem for higher-order ordinary differential equations," Journal of Mathematical Analysis and Applications, vol. 335, no. 2, pp. 1207-1218, 2007.

[13] Z. Du, X. Lin, and W. Ge, "Some higher-order multi-point boundary value problem at resonance," Journal of Computational and Applied Mathematics, vol. 177, no. 1, pp. 55-65, 2005. 
[14] P. W. Eloe and J. Henderson, "Positive solutions and nonlinear multipoint conjugate eigenvalue problems," Electronic Journal of Differential Equations, vol. 1997, no. 3, 11 pages, 1997.

[15] Z. Fu and Z. Du, "Existence of solution for a class of $n$ thorder multi-point boundary value problem," Journal of Applied Mathematics and Computing, vol. 33, no. 1-2, pp. 423-435, 2010.

[16] J. R. Graef, J. Henderson, and B. Yang, "Positive solutions of a nonlinear higher order boundary-value problem," Electronic Journal of Differential Equations, vol. 2007, no. 45, 10 pages, 2007.

[17] J. R. Graef, L. Kong, and Q. Kong, "Existence of three solutions for a higher-order boundary-value problem," Electronic Journal of Differential Equations: Conference, vol. 2009, no. 17, 10 pages, 2009.

[18] J. Henderson and R. Luca, "On a system of higher-order multi-point boundary value problems," Electronic Journal of Qualitative Theory of Differential Equations, vol. 2012, no. 49, 14 pages, 2012.

[19] Y. Ji and Y. Guo, "The existence of countably many positive solutions for some nonlinear $n$th order $m$-point boundary value problems," Journal of Computational and Applied Mathematics, vol. 232, no. 2, pp. 187-200, 2009.

[20] W. Jiang, "Multiple positive solutions for $n$ th-order $m$-point boundary value problems with all derivatives," Nonlinear Analysis: Theory, Methods \& Applications, vol. 68, no. 5, pp. 1064-1072, 2008.

[21] L. Liu, B. Liu, and Y. Wu, "Nontrivial solutions for higherorder $m$-point boundary value problem with a sign-changing nonlinear term," Applied Mathematics and Computation, vol. 217, no. 8, pp. 3792-3800, 2010.

[22] Y. Liu and W. Ge, "Solvability of a ( $p, n-p)$-type multi-point boundary-value problem for higher-order differential equations," Electronic Journal of Differential Equations, vol. 2003, no. 120, 19 pages, 2003.

[23] X.-J. Liu, W.-H. Jiang, and Y.-P. Guo, "Multi-point boundary value problems for higher order differential equations," Applied Mathematics E: Notes, vol. 4, pp. 106-113, 2004.

[24] P. K. Palamides, "Multi point boundary-value problems at resonance for $n$-order differential equations: positive and monotone solutions," Electronic Journal of Differential Equations, vol. 2004, no. 25, 14 pages, 2004.

[25] H. Su and X. Wang, "Positive solutions to singular semipositone $m$-point $n$-order boundary value problems," Journal of Applied Mathematics and Computing, vol. 36, no. 1-2, pp. 187-200, 2011.

[26] M. Zhang, Y. Yin, and Z. Wei, "Positive solution of singular higher-order $m$-point boundary value problem with nonlinearity that changes sign," Applied Mathematics and Computation, vol. 201, no. 1-2, pp. 678-687, 2008.

[27] X. Zhang, "Eigenvalue of higher-order semipositone multipoint boundary value problems with derivatives," Applied Mathematics and Computation, vol. 201, no. 1-2, pp. 361-370, 2008.

[28] D.-X. Ma, Z.-J. Du, and W.-G. Ge, "Existence and iteration of monotone positive solutions for multipoint boundary value problem with $p$-Laplacian operator," Computers \& Mathematics with Applications, vol. 50, no. 5-6, pp. 729-739, 2005.

[29] D.-X. Ma and X.-Z. Yang, "Existence and iteration of positive solutions to third order three-point BVP with increasing homeomorphism and positive homomorphism," The Rocky Mountain Journal of Mathematics, vol. 43, no. 2, pp. 539-550, 2013.

[30] B. Sun and W. Ge, "Successive iteration and positive pseudosymmetric solutions for a three-point second-order $p$ Laplacian boundary value problems," Applied Mathematics and Computation, vol. 188, no. 2, pp. 1772-1779, 2007.
[31] Y. Sun, X. Zhang, and M. Zhao, "Successive iteration of positive solutions for fourth-order two-point boundary value problems," Abstract and Applied Analysis, vol. 2013, Article ID 621315, 8 pages, 2013.

[32] Q. Yao, "Monotone iterative technique and positive solutions of Lidstone boundary value problems," Applied Mathematics and Computation, vol. 138, no. 1, pp. 1-9, 2003.

[33] Q. Yao, "Successively iterative technique of a classical elastic beam equation with Carathéodory nonlinearity," Acta Applicandae Mathematicae, vol. 108, no. 2, pp. 385-394, 2009. 


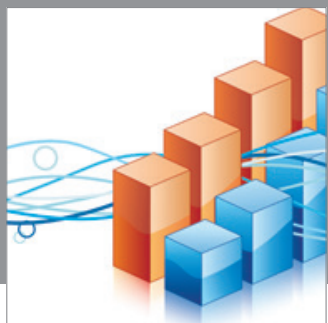

Advances in

Operations Research

mansans

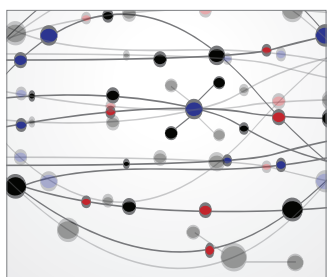

The Scientific World Journal
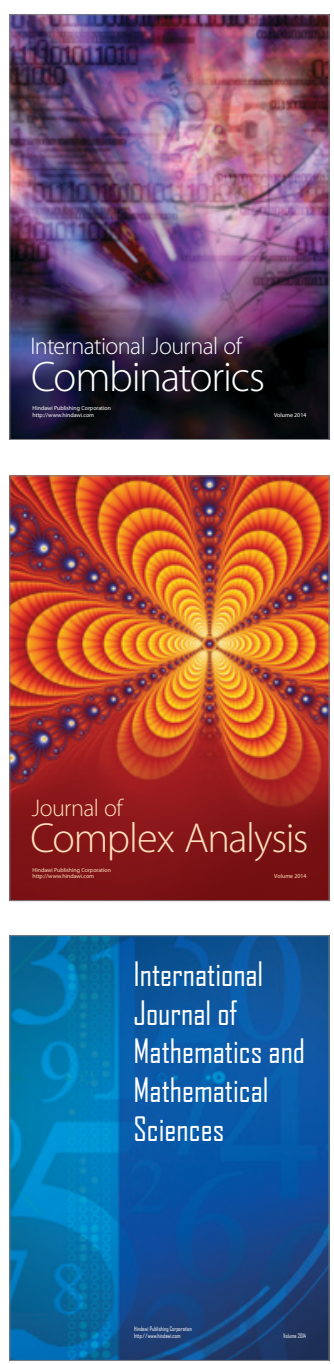
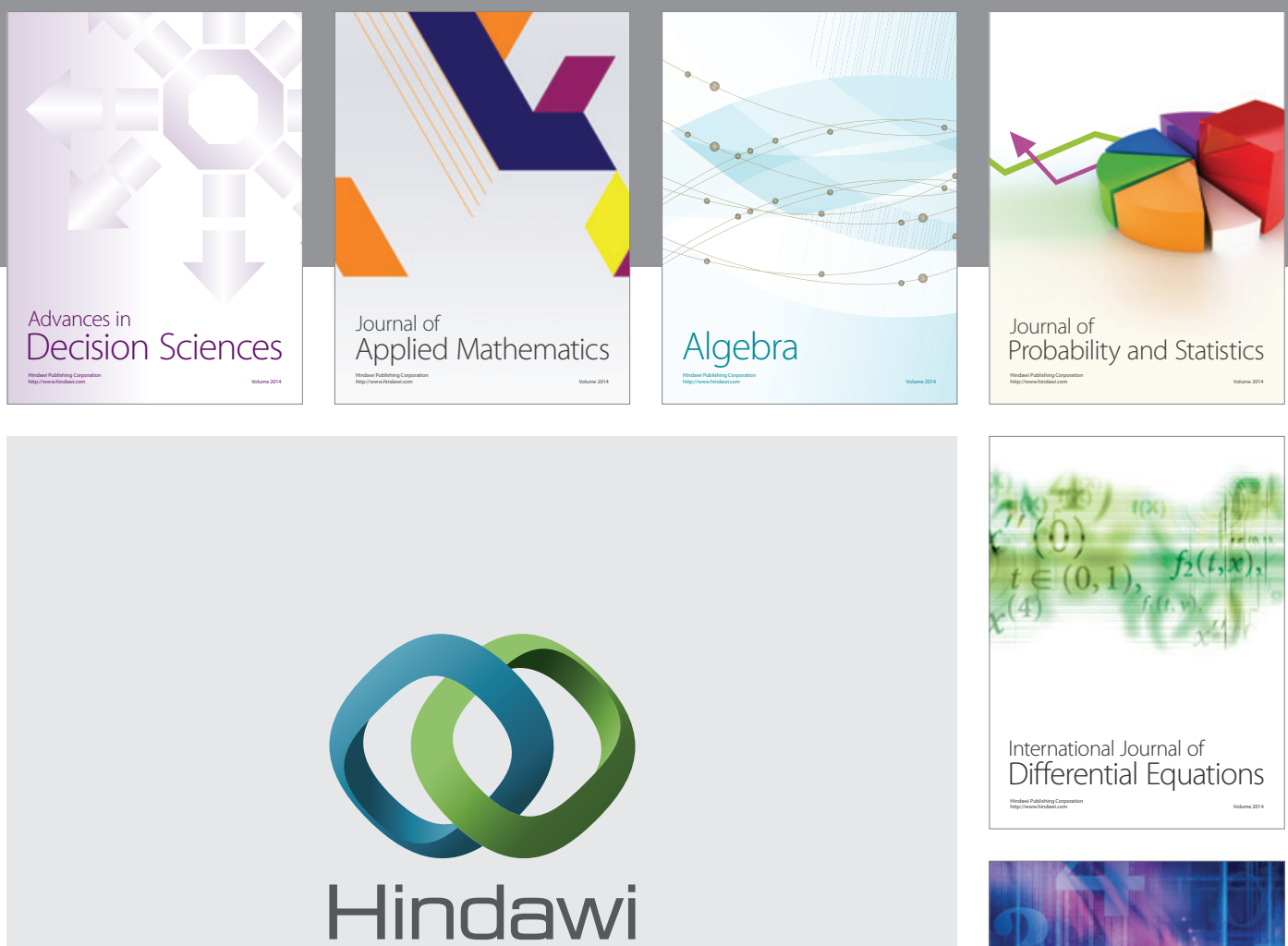

Submit your manuscripts at http://www.hindawi.com
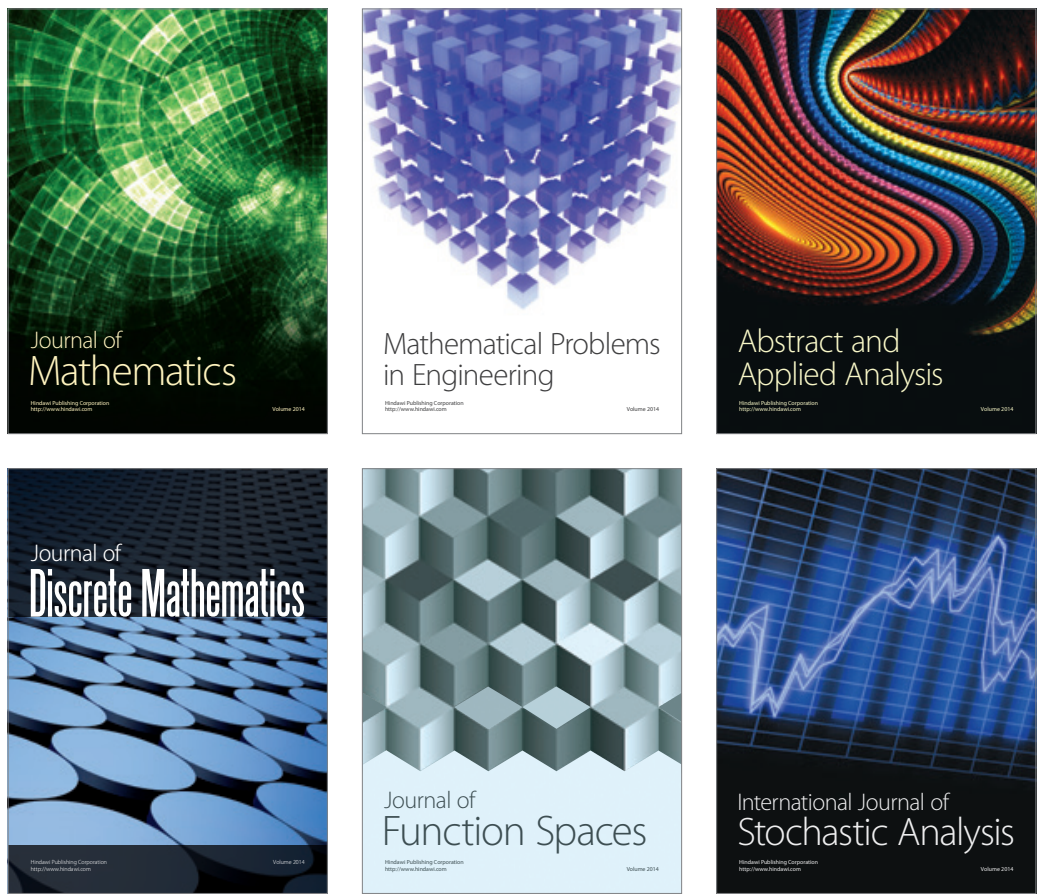

Journal of

Function Spaces

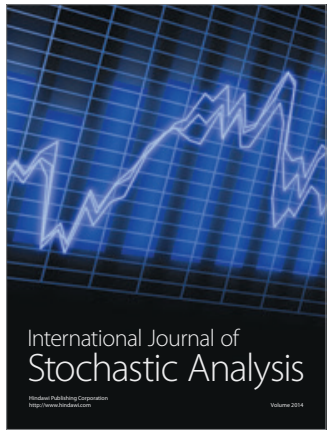

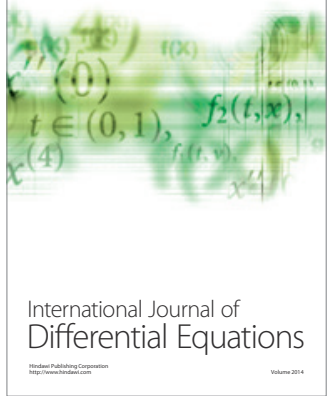
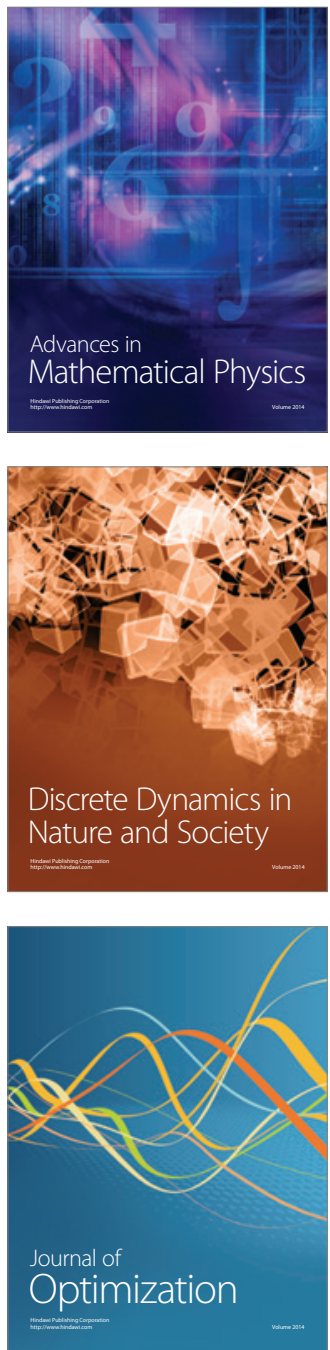